\title{
Laboreal
}

Volume $7 \mathrm{~N}^{\circ} 1$ | 2011

Psicodinâmica e psicopatologia do trabalho

\section{O trabalhar em serviços de saúde mental : entre o sofrimento e a cooperação}

El trabajo en los servicios de salud mental : entre el sufrimiento y la cooperación

Travailler dans des services de santé mentale: entre la souffrance et la coopération

Working at mental health services: between suffering and cooperation

S. Uchida, L. I. I. Sznelwar, J. O. Barros e S. Lancman

\section{(2) OpenEdition}

\section{Journals}

Edição electrónica

URL: http://journals.openedition.org/laboreal/8098

DOI: $10.4000 /$ laboreal.8098

ISSN: 1646-5237

\section{Editora}

Universidade do Porto

\section{Refêrencia eletrónica}

S. Uchida, L. I. I. Sznelwar, J. O. Barros e S. Lancman, « O trabalhar em serviços de saúde mental : entre o sofrimento e a cooperação », Laboreal [Online], Volume $7 N^{0} 1$ | 2011, posto online no dia 01 julho 2011, consultado o 10 outubro 2019. URL : http://journals.openedition.org/laboreal/8098 ; DOI : 10.4000/laboreal.8098

Este documento foi criado de forma automática no dia 10 outubro 2019.

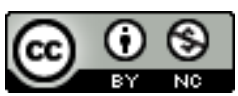

Laboreal está licenciado com uma Licença Creative Commons - Atribuição-NãoComercial 4.0 Internacional. 


\section{O trabalhar em serviços de saúde mental : entre o sofrimento e a cooperação}

El trabajo en los servicios de salud mental : entre el sufrimiento y la cooperación

Travailler dans des services de santé mentale : entre la souffrance et la coopération

Working at mental health services: between suffering and cooperation

S. Uchida, L. I. I. Sznelwar, J. O. Barros e S. Lancman

\section{NOTA DO EDITOR}

Manuscrito recebido em : Janeiro/2010

Aceite após peritagem em : Junho/2011

\section{Introdução}

1 No Brasil, até o final da década de 1970, a assistência oferecida no campo da saúde mental era centrada nas grandes instituições asilares, configurando uma determinada forma de compreensão da loucura e conseqüentemente de práticas terapêuticas, hoje consideradas bastante restritas e ultrapassadas. 0 modelo assistencial adotado, que tinha como foco a doença e a sintomatologia psiquiátrica manifesta, favorecia a utilização de práticas que terminavam por promover a permanência das pessoas com transtorno mental nas instituições hospitalares por tempo indeterminado gerando um grande contingente de pacientes crônicos, moradores dos hospitais. Em decorrência das internações prolongadas nestas instituições, conhecidas como manicômios, na maior parte das vezes precárias, e pela falta de opções terapêuticas que não as medicamentosas, os usuários dos serviços encontravam-se em situação de abandono e 
perdiam o contato com seus familiares e com redes sociais de suporte que pudessem oferecer qualquer possibilidade de desospitalização. Os hospitais psiquiátricos brasileiros chegaram a ser comparados com campos de concentração, ou seja, não asseguravam aos pacientes condições de vida e tratamento, e feriam seus direitos de cidadania (Machado et al 1978 ; Lancman, 1999).

2 Assim, em diálogo com contextos internacionais e reformas da assistência no campo da saúde mental, como as que ocorreram na Itália, França, EUA e Inglaterra, o Brasil, vem buscando produzir respostas mais adequadas diante das necessidades apresentadas pelas pessoas com transtornos mentais. Para tanto, no final da década de 1980, foram criados serviços extra-hospitalares no intuito de tentar garantir atendimento na própria comunidade, o mais próximo possível dos locais de moradia dos sujeitos e de seus familiares, reforçando assim uma rede social mais próxima, com vistas a evitar internações prolongadas e recorrentes. Outra etapa desenvolvida paralelamente foi a reorganização e humanização dos hospitais psiquiátricos brasileiros visando diminuir a situação de abandono e a falta de assistência e, por fim, foi dado início ao processo de desmontagem destes hospitais e de desospitalização dos usuários que haviam se tornado moradores (Brasil, 2005).

3 Atualmente um dos principais desafios deste processo, nomeado como Reforma Psiquiátrica, está na implementação e desenvolvimento de serviços de saúde mental na comunidade que consigam atender às necessidades cotidianas das pessoas com transtornos mentais. Compreende-se que essas necessidades não estão relacionadas apenas a cuidados de saúde, mas também a outras esferas da vida dessas pessoas, tais como : alimentação, moradia, atenção psicológica e psicossocial (Nicácio, 2003 ; Brasil, 2005 ; 2007 ; Barros, 2010).

4 Assim, a partir da década de 1990, o Ministério da Saúde do Brasil passou a definir e reorganizar a estruturação da política e dos serviços de saúde mental, propondo a adoção das redes municipais como referência para um tratamento integrado, a partir da interlocução entre os vários níveis de atenção em saúde. Foi nesta época que os Centros de Atenção Psicossocial (CAPS) foram designados como principal referência para o tratamento das pessoas com transtornos mentais (Brasil, 1992; 2005; Barros, 2010).

5 Essa proposta do Ministério da Saúde ganhou, em 2001, o estatuto de lei, que reafirmou a garantia e defesa dos direitos de cidadania das pessoas com transtornos mentais e apoiou a construção das redes de serviços que assegurassem esses direitos como uma forma para a organização da atenção em saúde mental (Brasil, 2001a,b ; Barros, 2010).

6 Segundo a legislação brasileira, os CAPS's são serviços vinculados à rede pública de saúde, estão inseridos na comunidade e oferecem atendimento especializado em saúde mental. Têm como missão acolher prioritariamente pessoas com transtornos mentais severos e persistentes em uma área de abrangência delimitada. Oferece três regimes de tratamento: intensivo, semi-intensivo e não-intensivo, variando segundo as necessidades das pessoas com transtornos mentais, em diferentes momentos da vida (Brasil, 2002).

7 Estes serviços estão organizados em diferentes modalidades : CAPS I, CAPS II e CAPS III, destinados a adultos, maiores de 18 anos e definidos por ordem crescente de porte, complexidade, abrangência populacional, horário de funcionamento, número de funcionários e de pessoas atendidas. Existem ainda aqueles especializados no 
atendimento a crianças e adolescentes com transtornos mentais (CAPS i), além daqueles destinados ao atendimento de pessoas que fazem uso abusivo ou tem dependência de substâncias psicoativas (CAPS ad) (Brasil, 2002).

8 A proposta é que o atendimento oferecido no CAPS seja diferente daquele oferecido no contexto hospitalar. 0 entendimento é que o foco do trabalho deva ser a vida da pessoa com transtorno mental e não apenas a sintomatologia psiquiátrica manifesta. Rede social, família, trabalho e habitação, por exemplo, são alguns dos eixos também trabalhados nestes serviços para que o sujeito possa realmente reconstruir sua vida para além do circuito saúde-doença. Procura-se ainda aprimorar e/ou desenvolver sua capacidade de gerar e gerir normas para a própria vida de forma a viabilizar sua circulação e, conseqüentemente, a realização de trocas sociais. Dessa forma, os atendimentos oferecidos no CAPS vão para além daqueles oferecidos dentro do espaço físico dessas instituições estendendo-se para a comunidade (Pereira, L.M.F et al, 2008).

9 Apesar de ter aproximadamente 30 anos, trata-se de um processo recente e que têm se desenvolvido com velocidades e constância distintas nos vários estados e cidades do país. Desta forma, em muitos destes lugares, a desmontagem do modelo hospitalocêntrico está acontecendo simultaneamente à implantação do modelo territorial. Assim não é difícil supor que possa haver uma desorganização do sistema de atenção como um todo, acarretando algumas dissonâncias, relacionadas, sobretudo, ao possível estado de desequilíbrio entre demanda e oferta ; ao desenvolvimento parcial, incompleto e provisório das ações assistenciais; a sobrecarga de trabalho e seus reflexos no cotidiano laboral dos agentes responsáveis pelo cuidado aos usuários.

10 As mudanças nos espaços físicos, do modelo centrado na internação para outro que prioriza o tratamento na comunidade e as práticas terapêuticas voltadas para a inserção dos usuários na comunidade, geram a necessidade de definição de novos processos de trabalho e de capacitação dos trabalhadores. Assim, esta nova perspectiva de cuidado e tratamento somada à desmontagem e implantação simultânea de modelos distintos, coloca desafios para os trabalhadores e gestores. Um deles está na superação das dificuldades operacionais e políticas para a implantação do modelo, pois a criação de uma estrutura desse porte requer além da implantação de um conjunto de serviços, a concepção e a criação simultânea de novas práticas e projetos organizacionais de atenção (Lancman, 2008).

11 Acrescenta-se ainda a precariedade e a morosidade do processo de constituição do sistema como um todo, gerando número insuficiente de serviços e de profissionais para a demanda desses serviços. Essa precariedade pode ocasionar um deslocamento de equipes para alguns serviços e o conseqüente esvaziamento de outros.

12 Além disso, esses novos equipamentos requerem a construção de processos de trabalho e de capacitação de profissionais que também sejam inovadores, afinal trata-se de um modelo novo, que pressupõe a construção de novas formas de saber-fazer e de novos paradigmas. Temos ainda o pouco investimento em recursos materiais que não asseguram que esses serviços, por vezes, funcionem em espaços adequados e que tenham a infra-estrutura necessária.

13 Como já mencionado, trata-se de uma proposta inovadora e, desta forma, tanto o processo de produção quanto a maneira como os CAPS's são organizados, fazem com que o conteúdo das tarefas e o desenvolvimento das atividades também estejam em 
construção. Há ainda o desafio de criar e instaurar formas de conexão com os outros níveis de atenção que compõem a rede de assistência à saúde.

Diante das possíveis dificuldades na implantação da nova Política de Saúde Mental, o Ministério da Saúde do Brasil, em parceria com o Ministério da Ciência e Tecnologia do Brasil, lançaram um edital para financiamento de projetos de pesquisa que pudessem contribuir neste processo. Foi no contexto desse edital que a pesquisa que será apresentada neste artigo foi desenvolvida. Teve como objetivo contribuir, através de uma abordagem baseada nos preceitos da psicodinâmica do trabalho, para a compreensão das vivências do trabalho dos sujeitos envolvidos de um determinado CAPS do município de São Paulo, que de alguma maneira poderia contribuir para o desenvolvimento de ações que ajudassem a aprimorar esse tipo de dispositivo de saúde pública (Lancman et al,. 2007).

O objetivo deste artigo é o de mostrar como a ação em psicodinâmica do trabalho (PDT), através da criação de um espaço de expressão e de circulação de experiências entre os trabalhadores, pode contribuir tanto para a elucidação, avanço e superação de alguns aspectos que dificultam a implantação do novo modelo quanto para o conhecimento das dificuldades e das estratégias criativas geradas no trabalho. Esperava-se encontrar indicações de sofrimento entre os trabalhadores, relacionado a diferentes aspectos tais como : a precariedade dos serviços onde trabalhavam, uma eventual descrença e o nãoreconhecimento dos esforços que realizavam para que o trabalho acontecesse.

Por outro lado, para dar conta de um desafio de tal magnitude, esperava-se também dar visibilidade para as estratégias e soluções criativas que os trabalhadores estivessem desenvolvendo, fruto da inteligência individual e coletiva, além de discutir seu papel na promoção da saúde mental destes. Procuramos ainda, contribuir para o avanço do novo modelo, ou seja, para o aprimoramento e exeqüibilidade das propostas de atenção em saúde mental, considerando-se os diferentes cenários de produção destes serviços; e, sobretudo, favorecer o processo de transformação do sofrimento em prazer no trabalho.

\section{O Cuidar em Saúde Mental}

17 A atividade de cuidar de pessoas com transtornos mentais é constituída, entre outros fatores, pelo encontro entre uma pessoa que sofre e outra encarregada de lhe propiciar a intervenção técnica que visa diminuir o seu sofrimento. Sendo o próprio aparelho psíquico o instrumento terapêutico principal do trabalhador, este tem que lidar tanto com o sofrimento do usuário quanto com o seu próprio. Um desafio importante é criar meios para que os trabalhadores possam realizar seu trabalho, evitando que se constitua um processo de sofrimento patogênico.

18 A possibilidade de o trabalhador contribuir com seu conhecimento e inteligência no aprimoramento do processo de trabalho é a forma de superação e transformação deste sofrimento em prazer. Afinal, o que mobiliza e motiva as pessoas para o trabalho é a retribuição simbólica pela contribuição que elas trazem ao trabalho. Este reconhecimento favorece a possibilidade de contribuição do profissional para a construção de uma produção de melhor qualidade e, ao mesmo tempo, possibilita o processo de realização de si. Um dos conceitos fundamentais que adotamos é o de que o trabalhar implica o fortalecimento do processo de identificação do trabalhador com o seu trabalho, através de um processo de reconhecimento do esforço, isto é, da 
contribuição individual e coletiva para se superar as dificuldades encontradas no confronto com o real.

Nessa perspectiva, para Dejours (2004), é central o conceito de identidade, entendido como uma armadura psíquica - resultado de um processo de unificação psíquica que constrói o sentimento de estabilidade, continuidade e integração de si no interior de uma história que é simultaneamente singular e social - que protege a saúde mental das pessoas no interior das instituições. Trata-se de uma construção intersubjetiva, pois depende do olhar do outro. Nesse sentido, é essencial que a organização do trabalho e o conteúdo das tarefas propiciem condições para a realização de si, fruto de uma ressonância simbólica entre atividade de trabalho e história pessoal.

Este processo de constituição identitária relacionada com o trabalho, que é constantemente colocada à prova, ocorre mediante reconhecimento da ação dos sujeitos que se dá pelo julgamento de outros,segundo dois prismas : o da utilidade e o da estética (Dejours, 2003). O primeiro é feito principalmente pelos superiores hierárquicos e, eventualmente, pelos clientes que avaliam a utilidade da ação, ou seja, sua eficiência e relevância organizacional, social e econômica. O indivíduo sente-se útil e pertencente ao grupo e à organização do trabalho quando reconhecido por esse julgamento. Já o julgamento estético remete à beleza e originalidade da solução, sendo formulado pelos pares, que reconhecem no sujeito as qualidades do seu saber-fazer e sua contribuição para o coletivo do trabalho. A originalidade no desempenho da ação leva o sujeito a não ser igual a outro par, torna-o único e singular. 0 julgamento é feito sobre o "fazer" e não sobre o "ser" e o sujeito para se re-assegurar como engenhoso e criativo, precisa passar pelo olhar e crítica do outro, que irá julgá-lo e reconhecer ou não as suas ações.

21 Isto evidencia que o trabalho, enquanto espaço de confronto entre o indivíduo - com suas crenças, valores e concepções - e o social, é permeado pelas condições concretas para sua realização, sua organização e pelas diferentes formas de concebê-lo.

Há, nesse sentido, a partir das pesquisas realizadas neste campo, evidências claras de que o trabalho não é neutro com relação à saúde das pessoas, mais especificamente com relação à saúde mental. Trabalhar pode promover o equilíbrio psíquico, a identificação com aquilo que se faz, a realização de si, porque ele é um meio essencial para a busca do sentido. Em suma, o trabalho é um elemento central na construção da saúde. Em situações onde não há margem de manobra, onde o trabalhador não pode contribuir com sua experiência e saber-fazer, ou não consegue realizar seu trabalho de acordo com seus princípios e crenças, ele está impedido de transformar o sofrimento em ações significativas que o levem ao prazer de realizar algo útil e belo (Sznelwar, 2003).

23 Assim, conhecer os aspectos que envolvem a organização do trabalho e a ação dos trabalhadores é um excelente meio de detectar os problemas na operacionalização das tarefas e suas implicações psíquicas, assim como as possíveis formas de superá-los. A PDT, entendida como clinica do trabalho, visa dar visibilidade e refletir sobre o trabalhar tendo como foco a racionalidade subjetiva (pathica) das ações. Isto significa pesquisar as relações entre os indivíduos e um coletivo (grupo de pessoas que compartilham regras de ofício ou experiências acerca das atividades realizadas).

A PDT ao estudar o trabalhar evidencia aspectos menos visíveis e conhecidos das relações de trabalho, tais como: o trabalho como construção identitária, as relações sofrimento e prazer que decorrem disso, a construção de defesas individuais e coletivas, o desenvolvimento da inteligência astuciosa, os riscos de alienação e a construção da 
inter-subjetividade (Dejours, 2009 ; Dessors, 2009 ; Lancman \& Uchida, 2003 ; Molinier, 2006).

Trabalhar em um serviço como o CAPS, requer que o trabalhador construa cotidianamente um conjunto de práticas que deverá nortear seu trabalho. $O$ trabalho prescrito é tênue e frágil tendo em vista que cada sujeito é singular e as intervenções também devem se constituir desta forma, ou seja, os profissionais e, conseqüentemente as equipes, devem construir seu processo de trabalho simultaneamente ao desenvolvimento da prática para realizá-lo. Este fato traz uma peculiaridade a este serviço e aos profissionais inseridos nele. Experimentar, viver o trabalhar é um desafio constante e exige o desenvolvimento de estratégias que se constituem numa inteligência astuciosa, própria a esses trabalhadores.

\section{Metodologia}

26 A ação em PDT foi desenvolvida em um distrito na cidade de São Paulo que aglutina alguns equipamentos de saúde mental, entre eles o CAPS, onde foi realizado este estudo. Inicialmente apresentamos o projeto de pesquisa, os objetivos e os princípios da abordagem para a equipe de forma que as pessoas que se dispuseram a participar dos grupos, resguardando o critério de voluntariado, pudessem construir em conjunto com os pesquisadores as discussões desenvolvidas durante as sessões de trabalho, de acordo com as propostas de ação neste campo (Heloani \& Lancman, 2004).

O grupo, num total de doze pessoas, foi constituído pela equipe de trabalhadores do CAPS e contou com a participação de profissionais diversos (psiquiatras, psicólogos, terapeutas ocupacionais, enfermeiras, assistentes sociais e farmacêutico). $\mathrm{O}$ caráter heterogêneo do grupo ocorreu em acordo com a própria equipe do CAPS que se organizava dessa forma, não privilegiava as especificidades profissionais na realização do seu trabalho nem criava uma estrutura muito hierarquizada entre os constituintes da equipe. Destaca-se aqui, que apesar das pesquisas em PDT procurarem trabalhar com grupos homogêneos, o método deve ser adaptado a cada situação de estudo encontrada e ser desenvolvido em acordo com as demandas dos trabalhadores e características dos grupos de trabalho.

O grupo se reuniu por aproximadamente dezoito horas, distribuídas em uma primeira etapa com sete sessões de discussão e de uma segunda etapa com duas sessões de validação organizadas de acordo com as possibilidades dos trabalhadores e do serviço. Entre as duas etapas ocorreu um intervalo de um mês para que os pesquisadores pudessem redigir um relatório. Essa dinâmica foi acordada com os trabalhadores antes do inicio do processo.

As sessões não seguiram nenhum roteiro pré-definido e desde o primeiro encontro a única instrução dada aos trabalhadores era que eles falassem sobre a vivência do trabalho deles. Os pesquisadores interferiram pouco no andamento das sessões limitando-se à condução dos grupos e a mediar para assegurar a palavra a todos. Ao término das sessões procurava-se fazer um breve resumo do que foi discutido assinalando alguns pontos considerados relevantes. Essa mesma prática foi, por vezes, utilizada no inicio da sessão seguinte para retomada das discussões.

Os pesquisadores procuraram manter uma escuta atenta ao conteúdo das falas, ao que era consensual, às discussões contraditórias, àquilo que emergia de forma espontânea 
ou não, ao que era dito ou omitido. As sessões foram gravadas e transcritas e todos os participantes assinaram o termo de consentimento livre e esclarecido previsto pela comissão de ética da Faculdade de Medicina da Universidade de São Paulo - USP.

31 Após a primeira etapa, os pesquisadores apresentaram um relatório provisório para os trabalhadores que participaram do grupo, como o intuito de discuti-lo, validá-lo e modificá-lo, segundo as suas críticas e contribuições. No processo de validação, por ser o momento em que os pesquisadores apresentam suas interpretações e assinalam pontos considerados importantes durante o processo de discussão, é comum haver grande mobilização dos trabalhadores que se identificam ou refutam as interpretações apresentadas. Nessas sessões de validação não é buscado um consenso, mas sim a garantia que todos se sintam representados naquilo que está escrito e que será divulgado. Inclusive, partes do relatório foram retiradas e outras acrescentadas para que a validação fosse assegurada.. O relatório validado apresenta então opiniões distintas, às vezes contraditórias, e também consensuais; vivências pessoais e compartilhadas, que se constituiu em um discurso comum representativo do trabalho daquele grupo.

Após essas sessões de validação incorporou-se as sugestões dos trabalhadores e foi redigido um relatório final, entregue a todos os participantes e incorporado ao relatório da pesquisa entregue ao Ministério da Saúde (Lancman, 2008).

Cabe explicitar que a PDT compreende que os pesquisadores também fazem parte de um coletivo de pesquisa. Dessa forma, é usual que, durante o processo, a equipe se divida e um dos membros não participe diretamente das sessões. Esse pesquisador acompanha a equipe que conduz as sessões durante todo o processo através de supervisões que visam ajudar na compreensão das dinâmicas estabelecidas, nos processos de constituição do espaço de palavra e das falas propriamente ditas, na formulação de hipóteses e de interpretações, assim como na construção de um discurso comum, baseado também na interpretação das vivências relatadas pelos integrantes da equipe. Esse recurso metodológico é importante para assegurar um trabalho interpretativo mais rico, fruto de um debate com a cooperação dos diferentes olhares, inclusive daquele que não esteve presente e que atua junto aos pesquisadores que estiveram diretamente envolvidos nas sessões no sentido de questioná-los e ajudá-los a entender o seu envolvimento e como estão desenvolvendo a dinâmica com os sujeitos que participam do grupo.

Os resultados serão apresentados aqui de duas maneiras. Primeiramente contextualizando o trabalho no CAPS estudado, de acordo com o cenário encontrado durante a pesquisa. Em seguida, será apresentada uma analise clínica ilustrada com trechos do relatório final validado com os trabalhadores, principalmente aqueles que estão relacionados com as vivências da equipe com relação ao seu trabalho.

Optou-se por apresentar diversos trechos do relatório na integra com o intuito de demonstrar parte do processo desenvolvido na ação em PDT. Este tipo de formulação é característica da maneira como são conduzidas e apresentadas as ações em PDT pela equipe responsável pela pesquisa, onde procura-se contextualizar o trabalho dos sujeitos e trazer para o espaço público as vivências deles em um formato que reflita o discurso comum construído nas sessões.

O relatório final para a PDT é muito mais do que uma síntese das discussões realizadas nos grupos. Ele tem como objetivo principal, a partir da escuta e observação clínica, sistematizar, elaborar interpretações e devolver aos integrantes do grupo um 
documento que seja por eles validados e que reflita o melhor possível aquilo que o grupo construiu conjuntamente. Para tal, é importante buscar recuperar aquilo que se vivenciou, refletir sobre o dito, mas também sobre o não dito, para permitir nos momentos de validação, um processo final de enriquecimento do conteúdo do documento que se tornará público. Espera-se que essa construção conjunta, onde de um lado é sistematizado o conteúdo das sessões, e de outro, os profissionais que conduziram as sessões apresentam suas impressões e interpretações, seja facilitador de processos de apropriação do sentido e da emancipação dos trabalhadores.

\section{Resultados}

\section{0 contexto do trabalho no CAPS}

Os processos de produção dos serviços do CAPS, assim como a maneira como é organizado o trabalho, fazem com que, entre outros aspectos, o conteúdo das tarefas e o desenvolvimento das atividades estejam continuamente em construção. Uma das características organizacionais marcantes destes serviços é a adoção de um modelo hierárquico mais horizontal onde a cooperação nas equipes é fundamental para a consecução dos processos de atenção. Há ainda o desafio de criar e instaurar formas de conexão com os outros serviços dos vários níveis de atenção que compõem a rede de assistência à saúde. Como essas conexões são muito frágeis, a organização do trabalho tem sido constituída muito mais por acordos internos da equipe. Assim, cada serviço vai construindo e definindo seu processo de trabalho a partir da realidade em que está instalada e dos recursos de que dispõe.

A necessidade de criar novas formas de trabalhar, a definição de novos processos de trabalho, a dificuldade de prescrição de atividades em serviços onde as rotinas são mal definidas, a falta de recursos necessários, fazem com que nem sempre os projetos terapêuticos que conseguem realizar estejam de acordo com aquilo que é previsto na reforma psiquiátrica e que norteia suas ações. Isso gera conflitos entre o sentido e as crenças que esses trabalhadores têm em relação àquilo que consideram um atendimento de qualidade em acordo com os preceitos que defendem e aquilo que podem efetivamente realizar. A construção de um modelo de atenção exige uma consistência interna entre os elementos que compõem o processo de trabalho objetivo, finalidade, instrumentos e a ação dos trabalhadores.

39 A mudança nos espaços físicos e de um modelo centrado na internação para outro, onde os usuários passam o dia e retornam para suas casas no final da jornada com foco na reabilitação psicossocial - práticas terapêuticas voltadas para a inserção dos usuários na comunidade - tal como proposta no CAPS, geram a necessidade de definição de novos processos de trabalho a serem construídos. São os confrontos e as contradições entre o processo de produção e criação do cotidiano das práticas assistenciais que vão possibilitar o desenvolvimento de um novo modelo de atenção e de uma redefinição do processo de trabalho.

\section{Ser do CAPS}

40 Os trabalhadores ao longo das sessões de reflexão usam comumente a expressão "ser do CAPS" como sinônimo de trabalhar no CAPS. Essa forma de apresentar sua pertinência 
reflete uma relação de trabalho que transcende um vinculo formal e demonstra um forte engajamento e compromisso. Mas denota também, uma sensação de pertinência que supera relações de trabalho usuais e remete para os trabalhadores responsabilidades e questionamentos que se confundem entre o que seriam as atribuições técnicas, as responsabilidades e limites do trabalho deles e a participação no projeto político de construção do CAPS. Essa sensação de pertinência vivenciadas pelos trabalhadores também os leva a um envolvimento particular com os usuários que vai para alem da clinica e/ou da reabilitação psicossocial. Essa forma de envolvimento, como veremos a seguir, traz conseqüências nos processos de trabalho, para as relações de sofrimento e prazer no trabalho e para a realização de si e construção identitária. Mas afinal o que significa para esse coletivo "ser do CAPS" ?

41 Ser do CAPS foi, inicialmente, para a equipe, uma experiência de constituição de um novo serviço, a partir da heterogeneidade das formações, experiências, histórias e trajetórias profissionais de cada um. Foi aprender a lidar com uma diversidade de percursos e estar aberto para a construção conjunta de um novo projeto de atendimento em saúde mental. Em alguns casos, dependendo da trajetória anterior, trabalhar neste local foi também ter a coragem para enfrentar o choque, o receio e a estranheza impostos pelo convívio tão próximo com a loucura. Foi ter consciência de que essa forma de convivência impunha outro tipo de adesão aos profissionais que viessem a trabalhar e aceitar os desafios de se inserir em um modelo de atendimento em construção sem, por vezes, ter clareza de que serviço era esse e que riscos trariam para aqueles que dele quisessem participar.

Nesse novo contexto de trabalho, ser do CAPS, significava não somente tratar o quadro clínico dos usuários, mas também abordar questões relacionadas à sua cidadania contribuindo, assim, com sua re-inserção social. Isto significava "uma nova esperança", uma nova forma de atividade dentro da rede pública de atenção em saúde mental, "de resgate da dignidade do paciente". Significava, também, fundar um novo espaço, novas relações institucionais, novos tipos de contratos terapêuticos, de atendimento e compreensão clínica. Participar de um projeto dessa natureza implicaria também na construção deles próprios, na revisão de paradigmas relacionados a antigas formas de atenção em saúde mental e um novo tipo de envolvimento com os pacientes, mais próximo e sem os aparatos de proteção e enquadre dos serviços psiquiátricos tradicionais.

o objetivo de promover a re-inserção dos usuários numa rede, nas relações comunitárias, na teia de relações sociais que, em grande parte, já estavam deterioradas é parte do trabalho do CAPs. É essa teia de sustentação do sujeito que precisava ser reconstituída e isso implica que os trabalhadores se mobilizem para ir em direção à comunidade e se preocupem com a vida dos pacientes para além da instituição. Não se trata, aparentemente, de uma simples questão de re-inserção, mas de considerar diversos aspectos relacionados à vida material, financeira, familiar e social dos usuários.

Isso significa reconhecer que o usuário não é só um sujeito com problemas de saúde mental, é também uma pessoa inserida num contexto social que traz consigo questões mais amplas, tais como: moradia, emprego, comida suficiente ou roupas, acesso ao sistema de saúde ou à educação. Isso significa também reconhecer que essas problemáticas estão dentro do escopo a ser abordado pelos trabalhadores do CAPs. Tudo isso se mistura, se é que poderia estar separados, da questão do sofrimento 
psíquico : são assuntos para quem ? Para os profissional do CAPs ou se trata de uma questão para toda a sociedade?

Soma-se a isso o fato de que esbarram na discriminação da qual a população de usuários é alvo, a começar pelo poder público que a exclui : "a pessoa é portadora de problema de saúde mental, ponto". Essa discriminação ocorre mesmo dentro do sistema de saúde e quando é preciso fazer um encaminhamento para outros serviços, por exemplo, para realizar exames clínicos relacionados a outras problemáticas que não as de saúde mental, encontram-se sérias dificuldades para conseguir atendimento.

Essa busca de condições para lidar com o usuário de uma maneira mais global significa construir novas formas de relações. Vai-se buscar, então, trabalhar de formas variadas e, em outros cenários, espera-se construir um novo saber sobre o fenômeno através de intervenções alternativas ao modelo médico hospitalar. No entanto, construir essas práticas no dia-a-dia é uma tarefa permeada por incertezas, necessidade de inventar novas formas de atuação, testá-las, de se deparar com dificuldades que, por vezes, transcendem ao trabalho técnico e no limite, ao próprio CAPs.

Em diversos momentos, os profissionais deparam-se com a necessidade de realizar práticas destoantes das que defendem como, por exemplo, os agendamentos de consultas médicas isoladas com ênfase na medicação. A questão não é somente o tipo de atendimento realizado, mas as dificuldades que encontram para criar os cenários e as formas de aproximação com o usuário da maneira como gostariam.

Por se tratar de um serviço público onde o ingresso é feito por concurso para serviços de saúde não específicos, muitos foram trabalhar ali quase por acaso. Isso foi para eles uma oportunidade, um desafio, mas também, um espaço de choque e contraste com outras referências de atendimento e de significação do paciente : sujeitos e cidadãos com direitos e deveres, portadores de doença mental, doentes? Os antigos códigos foram pouco a pouco colocadas em xeque, repensados, alguns mantidos e outros simplesmente deixadas de lado por não darem conta da realidade dos usuários e dos atendimentos dentro dessa nova lógica de cuidado.

Logo constataram que "ser do CAPS" era vivenciar um dia-a-dia sem rotina, sem uma delimitação definida, onde as atividades podiam ser somente provisoriamente estruturadas. Havia um esforço, por parte de alguns profissionais, de criar uma rotina ou, ao menos, exceto compromissos pré-agendados, tentar formatar um cotidiano de trabalho, certos tipos de atendimento, certos modos de atenção ao usuário que atendessem às peculiaridades de cada um e da variabilidade das situações que se apresentavam a todo momento. No entanto, a forma como o trabalho é organizado e as características da clientela deixam os trabalhadores perplexos, dada a fragmentação das atividades, imprevistos e a descontinuidade de muitos projetos: eram interrompidos o tempo todo, situações emergenciais interrompem atividades programadas, a falta de recursos materiais os obrigava a improvisarem $\mathrm{e}$ reorganizarem atividades planejadas com antecedência. Aqueles que conseguiam estabelecer uma determinada rotina enfatizavam a sua importância afirmando que se tratava de uma verdadeira âncora, que servia como referência e os protegia psiquicamente.

50 Ser do CAPS era construir uma organização de trabalho onde a equipe precisava estar aberta para lidar com o inusitado e o imensurável. Mas, afinal, o que era inusitado ? Para eles, depois de certo tempo de trabalho "nada é inusitado, tudo deixa de ser inusitado". Isso exigia que fossem flexíveis, mas que não perdessem a capacidade de se recompor, o 
que exigia novos modos de operar, novas decisões e muita discussão. Precisavam saber trabalhar com a errância, criando, assim, estratégias pessoais e coletivas para dar conta, organizar o que se desorganizava, dar suporte, estruturar.

51 As pessoas chegavam para trabalhar e já eram imediatamente absorvidas pelas demandas do trabalho, viviam constantemente situações em que não conseguiam se organizar, nem sempre se davam conta do que estava acontecendo e, por vezes, não tinham tempo para refletir ou aprofundar discussões com a equipe e planejar suas ações. Isso os levava a se envolverem com situações emergenciais, a perderem o foco e a se questionarem quanto a própria essência do CAPS.

Devido a esses questionamentos, acrescido do tempo elevado que os usuários permaneciam no CAPS, os trabalhadores apontavam críticas tais como : se não estariam afinal construindo um "belo terricômio" (em alusão aos antigos manicômios)? Os profissionais se questionavam se os pacientes embora ficassem mais internados no hospital, permaneciam agora internados no CAPS. Reconheciam, que apesar dos seus esforços, muitos usuários acabavam sendo internados em hospitais, o que para alguns significa um fracasso do próprio sistema e do próprio trabalho.

O tempo de permanência dos usuários e os limites do CAPS remetia a equipe a outros questionamentos relacionados ao conceito de alta, de desligamento do serviço e de reinserção do usuário em seu meio social, o que no limite significava para eles avaliar o êxito das estratégias terapêuticas desenvolvidas. Isso causava um sentimento de estranhamento e de angústia quando atendiam os mesmos usuários durante anos $\mathrm{e}$ constatavam: eles continuam no serviço. Era necessário refletir toda a teia de sustentação, não só do sujeito que era atendido, mas de sua rede social, o que tornava a cura e/ou re-inserção da pessoa com transtorno mental um processo ainda mais complexo. Afinal, o que é alta para esses usuários, ainda mais quando não encontram outros recursos de cuidados e sustentação?

Para alguns profissionais, o retorno de um determinado usuário era vivenciado como uma frustração e quando se conseguia dar alta para algum deles isso era um momento de recompensa pelo esforço feito. Para outros, a volta de algum usuário era entendida como positiva, pois, ao buscar atendimento, ele demonstrava vínculo com o serviço e com os profissionais que nele trabalhavam, era uma maneira de reconhecer que o CAPS e seus profissionais poderiam ajudá-lo.

O conceito de alta foi recheado de questões e controvérsias, pois, quando se avaliava as condições materiais, familiares e sociais do usuário, compreendia-se por que era tão difícil sair da instituição. Nesse momento, os profissionais pensavam se, de alguma maneira, o CAPS não seria um espaço mais leve, mais arejado na vida dessas pessoas, mais adequado, uma forma de proteção. Certos usuários eram emblemáticos nesse sentido, como um caso citado: além da severidade do quadro, ela apresentava um agravante, se ficasse em casa, ia ficar trancada, pois ela só tinha um irmão, cuja relação é difícil e a equipe não conseguiu trabalhar essa questão. Para essa usuária, o CAPS não era apenas um serviço de saúde mental : tratava-se de um local de cuidados, de poder contar com pessoas que se ocupavam, que davam visibilidade e sentido para a sua vida.

Participar de um projeto dessa natureza, "ser do CAPS" era também preocupar-se com a existência dos usuários fora do âmbito da instituição. De um lado, procurar melhorar a vida do usuário, aumentar as possibilidades de trocas, fazendo-o circular nos espaços reservados para os ditos normais; de outro, preparar a sociedade para recebê-lo nos vários locais públicos. De que adianta falar em re-inserção do usuário se não se coloca a 
presença da "loucura" no interior do espaço público? A verdade é que a sociedade, de uma maneira geral, acha que o lugar do louco é no hospício. Logo, se ele anda no museu ou desenvolve atividades em outros espaços, ele é visto com temor e receio.

Ser do CAPs implicava fadiga e, por vezes, a sensação de estar extenuado, dada a exigência contínua de atenção, de prontidão. Cada grito, cada batida de porta, cada atendimento, cada atividade ou projeto desenvolvido requeria uma atenção constante. Era necessário prestar atenção e tentar dar sentido a cada ato, afinal, todos os momentos na instituição podiam e eram considerados terapêuticos: "é no acaso que surgem as coisas mais criativas, que elas acontecem". Da mesma forma, crises, agressões, conflitos que exigiam a intervenção dos trabalhadores também podiam ocorrer a qualquer momento e era necessário manter uma vigilância contínua para dar conta do inesperado. Era preciso que diferentes competências estivessem disponíveis para manter os enquadres terapêuticos e ajudar a evitar problemas maiores devido a condutas inesperadas e, em alguns casos, até mesmo agressivas por parte dos usuários. Todo esse esforço, esse estado de alerta, cansava e deixava os profissionais exauridos. Às vezes, eles eram obrigados a desprender uma energia maior do que a que desejavam, o que, por vezes, os deixava irritados.

Esse novo setting (no sentido psicanalítico) de trabalho, reforçado pela crença que os profissionais tinham de que era necessário, como parte da relação terapêutica, do vinculo, estabelecer uma relação de proximidade com os pacientes. Significava, em alguns casos, deixar-se invadir, "aproximar e entrar na estória e não segregar, imergir". Mas, essa forma de envolvimento traz a questão dos limites : onde e como dar o corte ? A carga era pesada e no fim do dia tinha-se a impressão de que "foram atropelados por um caminhão".

59 Essa situação de trabalho os levava a terem que estar atentos uns aos outros, socorrer colegas que pediam ajuda, que buscavam apoio, pois, "ninguém dá conta sozinho". Ser do CAPS significava, então, criar uma equipe altamente solidária e cooperativa para que a ajuda e o apoio fossem efetivos. Criar uma teia de relações entre os trabalhadores que dessem suporte para aqueles que, por alguma razão, em certos momentos, não estavam em condições para atender os usuários. Isso produzia um clima de amizade, de afetividade, de equipe, de apoio mútuo, mesmo que não fosse explícito ou previsto. Era visível, para os pesquisadores, como os profissionais eram acolhedores, solidários e continentes em relação às angústias e dificuldades que um ou outro membro da equipe apresentava. Não censuravam e nem criticavam posturas que, em outro contexto, poderiam ser consideradas pouco técnicas e carentes da distância necessária para um bom cuidado. Dada a heterogeneidade de formações e a diversidade de propostas e projetos e de situações que vivenciavam, a construção desse trabalho, exigia cooperação, co-presença, colaboração, compreensão e flexibilidade.

Ser do CAPS exigia, então, um exercício complexo de estabelecimento de limites entre o pessoal e o profissional: viver uma situação onde quase não havia enquadramento protetor e as fronteiras entre a vida profissional e pessoal eram constantemente invadidas. Vários limites previstos em relações usuais entre terapeutas e pacientes nem sempre eram possíveis ou fáceis de exercitar em um contexto onde o contato entre profissionais e usuários era tão próximo e prolongado. Conforme exemplificavam, no atendimento, os terapeutas perguntavam para os usuários sobre sua história pessoal, familiar, as condições materiais, casa e espaço geográfico onde viviam. Mas, os pacientes, por vezes, subvertiam e também perguntavam ao profissional sobre sua vida 
particular, sobre o seu fim de semana, sobre sua família, o que fez ou deixou de fazer. 0 dilema se instaurava: responder ou não responder, até que ponto revelar, até que ponto compartilhar? Ante a insistência, cortava-se o assunto ou deixava-se invadir para não romper o vínculo, para que pudesse haver um trabalho terapêutico. Afinal, existia uma fronteira: proximidade não significa amizade. Mas, os profissionais percebiam e se questionavam acerca da desigualdade da relação, sabiam tudo da vida dos usuários, participavam da vida deles e, ao mesmo tempo, acreditavam que não deveriam se abrir tanto. Outro aspecto é que a equipe reconhecia que compartilhar da sua vida privada e pessoal, para alguns, era natural, mas para outros, não era vivenciado com a mesma tranqüilidade : o que é e o que deve ser consenso?

61 Os usuários testavam cada um dos profissionais, testavam a equipe como um todo, questionavam as possibilidades, os limites de cada um. Às vezes, tinha-se a impressão de que era necessário conviver com uma espécie de "espelho", pois o comportamento dos usuários colocava em xeque as barreiras psicológicas, fazia aflorar as angústias e, ao mesmo tempo, permitia estar mais próximo e menos defensivo. Havia risco, medo, mas era incontornável, fazia parte da expansão dos limites.

No entanto, alguns limites deviam ser discutidos e pactuados. Relataram como exemplo, a necessidade de determinados acordos que a equipe deveria fazer : não poderia haver discordâncias quanto a determinadas regras e procedimentos, todos deveriam atuar da mesma maneira, não devia haver exceção. Se uns diziam não $\mathrm{e}$ outros diziam sim, os usuários iriam atuar nas brechas existentes entre os membros da equipe para driblar o "não", para contornar a vivência frustrante que um limite exige. Orquestrar os limites da equipe e os limites pessoais era um trabalho que estava em constante estruturação.

Outro exemplo relatado se referia ao contato físico com os pacientes. Como lidar com limites entre hábitos da cultura e desejos mascarados, mas evidentes em rituais de cumprimento social, como por exemplo um beijo? Como lidar com esse tipo de comportamento quando se trata de "pacientes que não têm limites"? Afinal, não deixam de ser humanos e com desejos humanos! Como lidar quando o contato provoca reações diferentes nos vários profissionais ? O contato que, para um, pode ser tranqüilo, para outro, pode gerar mal-estar.

Os trabalhadores reconheciam a importância do enquadramento do contrato terapêutico como um limite essencial, uma condição que se colocava para o usuário : atende-se a tal hora, por tanto tempo, em tais atividades. Esse contrato impunha limites que visavam manter a "acuidade de compreender", fundamental na atividade terapêutica. Então, quando se buscava construir contratos, estava-se estabelecendo condições para o exercício do trabalho clinico, para que a relação terapêutica fosse eficaz. No entanto, o contrato terapêutico envolvia acordos para situações por vezes muito complexas que exigiam que ele fosse flexibilizado. Presenciar e entender situações complexas e saber agir com tranqüilidade nas horas em que elas ocorriam era parte do cotidiano desses trabalhadores, mas isso exigia uma presença de espírito que não tinha como ser prescrita, padronizada.

Outro incomodo relatado por um dos profissionais era relacionado à impotência técnica em relação às dificuldades de superação da doença mental. Tratava-se do momento em que o profissional sentia que esgotava o seu conhecimento, quando já havia pensado todas as possibilidades para aquele usuário e chegava um momento em que não 
conseguiam mais ajudar ou sentiam que tinham esgotado o arsenal. Como continuar a trabalhar nessas horas?

As peculiaridades próprias do CAPs influenciavam significativamente na vivência de todos. O desenvolvimento do projeto a que se propunham exigia que utilizassem de estratégias de cuidado intensivo e prolongado, o que requeria uma imersão profunda tanto dos usuários como de toda a equipe na continuidade da relação terapeuta-usuário de maneira intensiva e prolongada. Isso afetava de maneira significativa os trabalhadores, pois estar no CAPS significava desenvolver um trabalho praticamente sem fim, dada a natureza dos usuários e da sua permanência no serviço. $O$ fim, nesse caso, não estava relacionado a etapas concluídas, mas ao alcance de determinadas finalidades, que uma vez alcançadas abriam espaço para novas possibilidades e processos.

Os trabalhadores acreditavam que a maneira de organizar o trabalho devia ser tal que a instituição permitisse a integração dos usuários e não o isolamento, a exemplo do que acontecia nos hospitais psiquiátricos. Dessa forma, organizaram o serviço de forma tal, que à exceção da farmácia, todos os demais espaços eram acessíveis aos pacientes todo o tempo. Essa forma de trabalhar acarretava na falta de espaços privativos para a equipe corroborando a falta de limites entre os trabalhadores e os usuários Quase tudo ocorria às vistas de todos, sem privacidade e não havia praticamente espaço para se proteger, refletir, se recompor, "dar um tempo". A forma como organizavam o trabalho contribuía para que os limites entre relações profissionais e pessoais fosse muito difuso. Estabelecer fronteiras, espaço onde pudessem discriminar $o$ ato técnico do envolvimento necessário para este tipo de atendimento e, ao mesmo tempo, protegerse desta invasão para que ela não fosse excessiva e danosa, era um desafio cotidiano para essa equipe.

68 A própria peculiaridade da clínica das psicoses e a porosidade que se produzia entre terapeutas e usuários criava impasses e requeria que a equipe se auxiliasse para preservar o seu bem estar e permitir que o trabalho acontecesse. Todos estavam imersos neste espaço onde a fronteira entre a sanidade e a loucura era tênue, em que os usuários colocavam constantemente a equipe em xeque, em que a constituição de uma rede de cooperação, praticamente sem hierarquia, ajudava a transformar o sofrimento tanto em ações efetivas quanto em momentos de profunda satisfação. Isto requeria uma "recriação" constante das suas ações, o que criava uma sinergia a partir das diferentes competências e do envolvimento de cada um, da experiência individual e coletiva.

69 Lá se buscava construir ações em situações de grande penúria, onde era necessário recriar constantemente as práticas de saúde; mas, sobretudo porque lá se constituía um local de cuidados que buscava auxiliar os sujeitos a reconstruírem a vida. "O CAPS é um lugar de vida", um lugar onde as pessoas continuavam a trabalhar, apesar de todo o sofrimento engendrado pelo trabalho vivido.

70 Ser do CAPS "era se importar". O risco que se corria era que, na fratura a respeito da vida humana, as coisas que importavam eram jogadas na lata do lixo, era preciso trabalhar onde a vida se constituía, no momento em que a vida se constituía, nessa vida em paralelo. Vivia-se absolutamente dentro do âmago da vida humana, essa questão que era "como é que a gente vive numa sociedade que o povo, os seres humanos que estão vivendo, não importa para nada" ? Senão não estaria fazendo nada que interessava, porque não seria um assunto da vida, seria um assunto da burocracia, seria um assunto do mercado, que não interessava. É por isso 
que ela continuava, é por isso que fazia parceria com a equipe, era se importar, agir com compaixão.

\section{Discussão}

71 A equipe que participou deste processo era composta por profissionais que acreditavam em certas idéias relativas ao cuidado em saúde mental e que participaram ativamente da construção do projeto político que originou a reforma psiquiátrica e os CAPS's. Essas idéias modulavam as suas ações e eram constantemente confrontadas por uma realidade recheada de carências, insucessos, avanços e retrocessos decorrentes da implantação de um projeto político dessa natureza. O forte componente de posicionamento político era importante para que as pessoas continuassem a trabalhar, mas ficava a questão: até que ponto pode-se ancorar um sistema de atendimento no esforço isolado das equipes e não na construção de serviços e de uma rede efetiva? Seria importante que se aliasse também uma perspectiva de melhora da organização de serviços, da consolidação de um sistema de atendimento integrado que fortalecesse as experiências e propiciasse um aprimoramento das ações e das idéias.

72 Trazer para público a vivência do trabalho desta equipe permitiu conhecer seu modo de agir, seu saber-fazer, suas dúvidas e como era importante, além do engajamento, se deixar afetar pelo outro, isto é, trabalhar com compaixão. Com a experiência acumulada e o sentido que encontraram nos paradigmas que as originaram e que norteiam suas práticas, construíram sentido no trabalho e estabeleceram pontos de ancoragem que lhes permitiam encontrar a sinergia necessária para continuar trabalhando apesar das carências, das dificuldades que um serviço dessa natureza impõe e da falta de uma rede de saúde mais constituída e que, de fato, servisse de apoio.

73 A engenhosidade dos trabalhadores e a cooperação permitiam que o trabalho fosse realizado a contento, afinal, não havia um modo prescrito de trabalhar que desse conta dos eventos presentes neste tipo de cuidado. O exercício dessa engenhosidade, a busca de soluções, pequenos sucessos cotidianos, a crença de que estavam produzindo um trabalho de qualidade e o reconhecimento que encontravam, sobretudo junto às pessoas que eram atendidas e seus familiares, seriam fundamentais para a construção da sua própria saúde mental, pois são fontes da construção de sentido, fonte de prazer para trabalhar. A maneira como a equipe era organizada e as relações de cooperação horizontal e vertical que se constituíram neste CAPS, propiciaram também condições para o processo de realização de si e da construção de um coletivo profissional (Dejours, 2009).

74 A integração da equipe, a cooperação e a solidariedade eram pontos fundamentais que ajudavam os trabalhadores a se protegerem dos sentimentos de impotência, das coisas que não davam certo, da inoperância do sistema que dificultava um trabalho já tão árduo. A cooperação decorria de um processo de confiança e reconhecimento dos pares que os auxiliava a não entrarem em colapso, no sentido psíquico, diante da falta de reconhecimento vertical. No caso do julgamento de beleza, que é feito entre pares, isso ocorria pela constituição de uma equipe que era capaz de enxergar e de dar retorno sobre o trabalho bem feito do outro. Já no caso do julgamento de utilidade, este ocorria pelo reconhecimento da chefia imediata, que também fazia parte da equipe (Dejours, 2003 ; Hubault \& du Tertre, 2008). Aliado a esses aspectos, um profundo sentimento de gratidão (Molinier, 2006, pp. 146-147) por parte dos pacientes e familiares, reforçava 
esta possibilidade de encontrar sentido e prazer no trabalho. Com relação ao reconhecimento de pares mais distantes, de integrantes de outras equipes e de outros CAPS, os contatos eram pouco freqüentes, resumindo-se a alguns encontros organizados anualmente, dos quais, somente parte da equipe participava reafirmando a sensação de isolamento. Como conceitua Dejours, o reconhecimento, em especial do reconhecimento de beleza e o de utilidade são elementos chaves para a construção identitária e saúde mental no trabalho (Dejours, 2004).

75 No que diz respeito às possibilidades de avaliação por outras instâncias do sistema de saúde, a distância era significativa, fato que dificultava um processo de avaliação baseado no real do trabalho. Isto tem semelhança com outras situações de trabalho em saúde pública, onde é muito difícil definir quais são os limites do cuidado (Sznelwar, Uchida \& Mascia, 2008).

Além disso, em se tratando de uma relação de serviço que se constrói ao longo do tempo, o processo de avaliação é ainda mais complexo, pois há uma série de aspectos intangíveis e imateriais característicos deste tipo de trabalho que são dificilmente reconhecidos, ficando na invisibilidade (du Tertre, 1999, 2002 ; Hubault \& Bourgeois, 2001).

77 Não se pode perder de vista que o "cuidar" destes profissionais é desestabilizador, portanto, é importante que tenham acesso à supervisão e a apoio terapêutico quando necessário, como estratégia de fortalecimento das equipes e conseqüentemente de cada trabalhador em particular. Molinier $(2000,2009)$ discute a questão do cuidar (care) colocando em evidência a importância da compaixão e das questões de gênero e demonstrando o caráter desconhecido dessa atividade.

Pelo fato de não existirem formalmente dispositivos de apoio, seria importante que houvesse uma estrutura de sustentação, aliada à construção de outros "espaços públicos de troca e de deliberação", como a realização de mais simpósios e seminários para que houvesse mais compartilhamento de experiências com outras equipes que atuam em outros CAPS, e com outras equipes de serviços de referência da região com as quais, devem constituir a rede de atendimento.

79 Viver um processo de mudança de paradigma, de criação de novas práticas assistenciais e de um modelo de atenção significa ser ator e testemunha de algo mais profundo de desestruturação e de reconstrução. Este processo é longo e, muitas vezes, requer mais de uma geração de trabalhadores. Há ainda o risco sempre presente de retrocessos e, sobretudo, de uma não implantação plena do modelo proposto. Foi o que ocorreu com a equipe estudada, sentiam-se únicos, isolados e aguardavam a constituição do resto da rede com a qual pudessem somar e dividir esforços. Como não é possível aguardar, diante das necessidades de atendimento da comunidade, desenvolveram um sistema de cuidado provisório e parcial em relação ao previsto.

80 A precariedade existente nos serviços de saúde mental, dos aspectos organizacionais e de conteúdo das tarefas de cada profissional além dos aspectos psíquicos decorrentes do trabalhar com pessoas que têm transtornos mentais de maior ou menor gravidade, é indissociável do impacto disso tudo nas relações de sofrimento/prazer no trabalho da equipe. Isto resulta do fato de que a vivência desses trabalhadores seja determinada pelos cenários definidos por todas estas variáveis e pela história singular de cada trabalhador. 
81 Na organização do trabalho do CAPS há uma racionalidade clínica implícita que dá sentido à atividade, fruto de idéias e de concepções que constituem uma maneira de ver as práticas em saúde mental e que dão sentido para os trabalhadores. Não significa que sejam situações onde não haja conflitos e contradições, mas que há algo que serve como argamassa, como fator de ligação para as pessoas da equipe, como substrato para fomentar o tipo de atendimento proposto e, pelo menos em parte, praticado. As práticas clínicas que os trabalhadores desenvolvem de acordo com o modelo conceitual com o qual estão identificados norteiam a organização do trabalho e o conteúdo das tarefas e dão sentido às ações desenvolvidas.

Mesmo com todas as falhas e a falta de infra-estrutura, apesar do sofrimento devido à lentidão na implantação das melhorias e à sensação de que poderiam fazer mais pelos usuários, há uma visão de futuro possível. Há uma sensação de que são uma espécie de vanguarda de um novo tipo de atendimento, mesmo que isto engendre dificuldades e, muitas vezes, exija um comprometimento quase militante dos integrantes da equipe.

\section{Conclusão}

Acredita-se que, com esta ação em PDT foi possível ajudar na compreensão das implicações para a saúde dos profissionais de trabalhar no CAPS e do novo modelo de cuidado em saúde mental de modo a facilitar ações que ajudem a contribuir na implantação desse tipo de serviço e no seu aprimoramento. Espera-se, ainda, contribuir para ações de melhoria e de consolidação deste tipo de prática terapêutica, para que seja possível, com o engajamento dos trabalhadores, evitar que as vivências no trabalho se transformem em sofrimento patogênico, reduzindo o risco do aparecimento de problemas de saúde entre os trabalhadores e de impedimentos para a realização do trabalho a contento. Acreditamos que a invisibilidade desses aspectos pode prejudicar a própria implantação de um sistema de saúde baseado em práticas de atendimento mais globais e que considerem os pacientes como cidadãos e sujeitos.

Ao se propiciar condições para o melhor conhecimento do real do trabalho dessas equipes, é possível evidenciar e sensibilizar as pessoas responsáveis pelos níveis de decisão sobre as políticas de saúde pública no Brasil, para que invistam na consolidação de uma rede de saúde mental que leve em conta o trabalhar e a subjetividade dos trabalhadores.

Acredita-se que a possibilidade de o trabalhador contribuir com seu conhecimento e com sua inteligência na construção de um trabalho melhor é a forma de superação e transformação do sofrimento engendrado pelo real do seu trabalho em prazer, garantindo condições para que aquilo que faz continue a fazer sentido e que seja uma perspectiva de realização profissional e pessoal. Nesse sentido, é essencial que a organização do trabalho e o conteúdo das tarefas propiciem condições para a realização de si, fruto de uma ressonância simbólica entre atividade de trabalho e história pessoal e os confrontos engendrados pelo trabalho.

Isto evidencia que o trabalho, enquanto espaço de confronto entre o indivíduo - com suas crenças, valores e concepções - e o real, é permeado pelas condições concretas para sua realização, sua organização e pelas diferentes formas de concebê-lo. Conhecer os aspectos que envolvem a organização do trabalho e sua execução é um excelente 
meio para detectar os problemas na operacionalização das tarefas e suas implicações psíquicas e as possíveis formas de superá-los.

87 As contribuições da PDT vêm no sentido de evidenciar aspectos menos visíveis e conhecidos das relações de trabalho, tais como: o trabalho como construção identitária, as relações sofrimento e prazer que decorrem disso, a construção de defesas individuais e coletivas, o desenvolvimento da inteligência astuciosa, os riscos de alienação e a construção da inter-subjetividade. Todavia, não se trata de apenas colocar em evidência e trazer conhecimentos sobre o trabalhar das pessoas, o fundamental de uma ação em psicodinâmica do trabalho é propiciar meios para que os trabalhadores possam se apropriar do sentido do seu trabalho, transformando-o e, sobretudo, criando condições para que se trilhem caminhos visando à emancipação dos sujeitos.

Neste sentido, essa ação realizada junto a uma equipe de trabalhadores do CAPS, em São Paulo, Brasil, traz uma série de questões e desafios para todos os serviços assemelhados no país, que hoje totalizam mais de mil unidades. Dentre eles cita-se a importância da constituição de equipes com alto grau de autonomia e que possam se constituir em verdadeiros espaços de cooperação entre diferentes profissionais que trabalham visando objetivos comuns. A cooperação e a disponibilidade dos sujeitos desta equipe para trabalhar juntos podem ser consideradas como um exemplo ímpar que se contrapõe ao lugar comum encontrado nas práticas de gestão mais comuns nas empresas privadas e públicas. As práticas mais prevalentes privilegiam o indivíduo em detrimento do coletivo, reduzem ou eliminam os espaços de troca, não propiciam condições para deliberação coletiva, favorecem a gestão por evidências em resultados mensuráveis, definem metas que não correspondem à realidade. Um sistema de saúde contaminado por este tipo de ideologia de gestão é praticamente incompatível com a existência de espaços de trabalho como o CAPS estudado que, apesar de todas as carências e dificuldades poderia ser considerado como um exemplo a ser seguido.

\section{BIBLIOGRAFIA}

Barros, Juliana de Oliveira. (2010). A construção de projetos terapêuticos no campo da saúde mental : apontamentos acerca das novas tecnologias de cuidado. Dissertação de Mestrado, Faculdade de Medicina da Universidade de São Paulo.

Brasil (1991). Ministério da Saúde. Portaria 224 de 29 de Janeiro de 1992. (http:// www.saude.mg.gov.br/atos_normativos/legislacaosanitaria/estabelecimentos-de-saude/ saudemental/ PORTARIA_224.pdf. Acesso em 15 de novembro de 2009).

Brasil (2001a). Lei Federal 10.216 de 06 de Abril de 2001.

(http://dtr2004.saude.gov.br/susdeaz/legislacao/arquivo/12_Lei_10216.pdf. Acesso em 18/11/06).

Brasil (2001b). Ministério da Saúde. Conselho Nacional de Saúde. Comissão Intersetorial de Saúde Mental. III Conferência Nacional de Saúde Mental. Brasília. 
Brasil (2002). Ministério da Saúde. Portaria 336 de 19 de Fevereiro de 2002. (http:// dtr2001.saude.gov.br/sas/PORTARIAS/Port2002/Gm/GM-336.htm. Acesso em 01/05/07).

Brasil (2005). Ministério da Saúde, Secretaria de Atenção à Saúde/DAPE, Coordenação Nacional de Saúde Mental. Reforma Psiquiátrica e política de saúde mental no Brasil, Conferência Regional de Reformas dos Serviços de Saúde Mental ; 15 anos depois de Caracas. OPAS. Brasília (DF) : Ministério da Saúde.

Brasil (2007). Ministério da Saúde. Secretaria de Atenção à Saúde/DAPE. Saúde Mental no SUS : acesso ao tratamento e mudança do modelo de atenção.Relatório de Gestão 2003-2006. Brasília. Dejours C. (2003). L'évaluation du travail à l'épreuve du réel. Paris : INRA Editions.

Dejours, C. (2004). Addendum, Da psicopatologia à psicodinâmica do trabalho. In Lancman S., Sznelwar L.I., Christophe Dejours - Da psicopatologia à psicodinâmica do trabalho (pp. 49-106). Rio de Janeiro : Paralelo15.

Dejours C. (2009). Le travail vivant - Travail et émancipation, tome II, pp. 73-112, Paris : Payot.

Dessors, D. (2009). L'intelligence pratique, Travailler, $\mathrm{n}^{\circ}$ 21, 61-68.

Du Tertre C. (1999). Intangible Interpersonal Services. Adjointment and Reduction of Working Hours. Toward New Political Economy Tools, The french Case. Services industries Journal, 19.

Du Tertre C. (2002). Activités immatérielles et relationnelles : quels nouveaux enjeux pour les secteurs et les territoires. Géographie, Économie et Société, 4, 181-204.

Heloani R, \& Lancman S. (2004). Psicodinâmica do Trabalho : o método clínico de intervenção e investigação do trabalho. Rev. Produção ; 14 (3), 77-86.

Hubault F. \& Bourgeois F. (2001). La relation de service : une convocation nouvelle pour l'ergonomie In : Hubault, F., La relation de service, opportunités et questions nouvelles pour l'ergonomie. (PP. 5-32), Toulouse : Octarès Editions.

Hubault F. \& Du Tertre C. (2008). Le travail d'évaluation, In Hubault F (coord.), Evaluation du travail, travail d'évaluation, Actes du séminaire Paris1 4-6 juin 2007 (pp. 95-114). Toulouse: Editions Octarès,

Lancman S, Pereira LMF, Uchida S, Sznelwar LI, et all. (2007). Transformação do modelo de atenção pública em saúde mental e seus efeitos no processo de trabalho e na saúde mental dos trabalhadores. Relatório Final. São Paulo (SP) : CNPq. Processo 554503/2005

Lancman S. \& Uchida S. (2003). Trabalho e subjetividade . Caderno de Psicologia Social e do Trabalho,6, 77-88.

Lancman, S (org), (2008). Políticas publicas e processos de trabalho em saúde mental. Brasília : Paralelo 15.

Lancman, S. (1999). Loucura e Espaço Urbano : Franco da Rocha e o asylo do Juquery. Rio de Janeiro : Editora Te-Corá.

Lancman, S., Sznelwar. L. I., Uchida. S., Alonso, C.M.C., \& Juns, A.G. (2008). Ação em psicodinâmica do trabalho : contrbuições sobre o trabalhar em saúde mental. In Lancman, S (org), Políticas publicas e processos de trabalho em saúde mental. Brasília : Paralelo 15.

Machado, R., Loureiro, A., Luz, R., \& Muricy, K. (1978). Danação da norma : medicina social e constituição da psiquiatria no Brasil. , Rio de Janeiro : Edições Graal.

Molinier P. (2000). Travail et compassion dans le monde hospitalier. Les Cahiers du Genre. La relation de service : regards croisés, 28, 49-70. 
Molinier, P. (2006). Les enjeux psychiques du travail, pp. 243-261, Paris : Payot.

Molinier, P. (2009). Quel est le bon temoin du care In Molinier, P ; Laugier, S. \& Paperman, P. (dir) Qu'est-ce que le care? (pp. 233-251). Paris : Payot.

Nicácio, MFS. (2003). o Desafio da Reforma Psiquiátrica. In : Utopia da realidade : contribuições da desinstitucionalização para a invenção de serviços de saúde mental [tese]. Campinas : Faculdade de Ciências Médicas, Universidade Estadual de Campinas, p. 33-70.

Pereira, L.M.F., Rizzi, H.J., \& Costa, A.C.F. (2008). Análise sócio-histórica das políticas em saúde mental no Brasil, in Lancman, S (org), Políticas publicas e processos de trabalho em saúde mental. Brasília: Paralelo 15.

Sznelwar L. I. (2003). Working and Impediment: The Causes and Consequences of Inadequate Task Content and Work Organisation. XVth Triennal Congress of the International Ergonomics Association, 7th Joint Conference of Ergonomics Society of Korea / Japan Ergonomics Society. Seul : Ergonomics in the Digital Age.

Sznelwar, L.I., Uchida, S. \& Mascia, F. (2008). De l'impossible evaluation de ce qui n'a pas de limite, et des consequences pour ceux qui ont quand même à y faire face. In Hubault, F. (coord) Évaluation du travail, travail d'évaluation, (pp. 41-64). Toulouse : Octarès.

\section{RESUMOS}

A proposta central deste artigo é a de apresentar o resultado de uma ação em psicodinâmica do trabalho (PDT), desenvolvida com uma equipe de trabalhadores de um Centro de Atenção Psicossocial (CAPS), localizado na cidade de São Paulo, Brasil. Trata-se de um serviço especializado no atendimento em saúde mental, destinado, prioritariamente, às pessoas com transtornos mentais severos e persistentes. Buscou-se, por meio de uma ação em PDT, compreender as vivências dos trabalhadores, a relação sofrimento e prazer no seu trabalho, assim como as estratégias desenvolvidas para obter resultados, identificando fatores críticos e formas para vencê-los. A criação de espaços coletivos de discussão que possibilitassem identificar e dar visibilidade às estratégias de trabalho criadas pela inteligência individual e coletiva dos sujeitos em sua experiência concreta é um ponto fundamental desta abordagem. Considera-se que a inclusão da vivência dos trabalhadores para o aprimoramento da implantação da política pública de saúde mental brasileira possibilite um aprimoramento das instituições.

El propósito de este trabajo es presentar el resultado de una acción en psicodinámica del trabajo (PDT), desarrollado con un equipo de trabajadores de un Centro de Atención Psicosocial (CAPS), que se encuentra en Sao Paulo, Brasil. Es un servicio especializado en atención de salud mental dirigido principalmente a personas con trastornos mentales severos y persistentes. Buscamos, a través de una acción en PDT, comprender las experiencias de los trabajadores, la relación sufrimiento y el placer en su trabajo, así como las estrategias desarrolladas para lograr resultados mediante la identificación de factores críticos y los medios para superarlos. La creación de espacios colectivos de discusión que permita identificar y dar visibilidad a las estrategias de trabajo creado por la inteligencia individual y colectiva de los sujetos en su experiencia real es un punto clave de este enfoque. Se considera que la inclusión de las experiencias de los trabajadores para mejorar la aplicación de las políticas públicas sobre salud mental en Brasil permite mejorías en las instituciones.

Le but de cet article est de présenter le résultat d'une action en psychodynamique du travail (PDT), développée avec une équipe de travailleurs d'un Centre d'Attention Psychosociale (CAPS), situé à São Paulo, Brésil. Il s'agit d'un service spécialisé dans les soins de santé mentale visant 
principalement les personnes ayant des troubles mentaux graves et persistants. En développant une action en PDT, le but a été de comprendre les expériences des travailleurs, la relation entre souffrance et plaisir dans le travail, ainsi que les stratégies élaborées pour atteindre les résultats, en identifiant les facteurs critiques et les moyens de les surmonter. La création d'espaces de discussion collective pour identifier et donner de la visibilité au travail et aux stratégies mises en place grâce à l'intelligence individuelle et collective des sujets à partir de leur expérience réelle est un point clé de cette approche. La valorisation de l'expérience des travailleurs dans la mise en œuvre des politiques publiques concernant la santé mentale au Brésil permettrait une amélioration du rôle des institutions.

The main purpose of this paper is to present the result of an action in Psychodynamic of Work, developed within a team of workers of a Psychosocial Center of Attention (CAPS - Centro de Atenção Psicossocial), located in São Paulo, Brazil. It is a specialized facility in mental health attention which prioritizes people with severe and persistent mental disorders. We tried to comprehend the workers experience, their relationship between psychic suffering and pleasure at work, as well as the strategies to gain results, identifying critical factors at work and ways to overcome these difficulties, through a Psychodynamic of Work approach. The creation of a collective space of discussion that enabled the identification and gave visibility to work strategies created by the collective and individual intelligence of subjects in their concrete experience is fundamental to this approach. We consider that the inclusion of workers experience to the improvement of Brazilian mental health public policy implantation allows an improvement of the institutions.

\section{ÍNDICE}

Mots-clés: système public de santé, santé mentale et travail, coopération et équipes de travail, action en psychodynamique du travail

Keywords: public system of health, mental health and work, cooperation and team work, Psychodynamic of Work approach

Palavras-chave: sistema público de saúde, saúde mental e trabalho, cooperação e equipes de trabalho, ação em psicodinâmica do trabalho

Palabras claves: sistema de salud pública, salud mental y trabajo, la cooperación y el trabajo en equipo, acción en psicodinámica del trabajo

\section{AUTORES}

\section{S. UCHIDA}

Fundação Getulio Vargas , Av. 9 de Julho, 2029 - Bela Vista , CEP : 01313-902 - São Paulo, SP-Brasil Seiji.uchida@fgv.br

\section{I. I. SZNELWAR}

Escola Politécnica da USP - Departamento de Engenharia de Produção, Av. Prof. Luciano

Gualberto, travessa 3 ํo 380 - CEP 05508-010 - São Paulo, SP-Brasil

laertesz@usp.br 


\section{J. O. BARROS}

Faculdade de Medicina da Universidade de São Paulo, Av. Dr. Arnaldo, 455 - Cerqueira César CEP : 01246903 - São Paulo, SP-Brasil

Juliana.obarros@usp.br

\section{S. LANCMAN}

Faculdade de Medicina da Universidade de São Paulo, Departamento de Fisioterapia, Fonoaudiologia e Terapia Ocupacional, R. Cincinato Braga, 184, apto 51, CEP. 01333-010. São Paulo, SP-Brasil

lancman@usp.br 